\title{
STRUCTURAL AND FUCNTIONAL PARAMETERS OF THE CARDIOVASCULAR SYSTEM DURING ATRIAL FIBRILLATION IN PATIENTS AFTER STROKE
}

DOI: 10.36740/WLek202103115

\author{
Lyudmila A. Kamyshnikova, Olga A. Efremova, Ekaterina V. Bondarenko, Natalya I. Obolonkova, \\ Olga A. Bolkhovitina, Maryam W. Yusuf \\ BELGOROD STATE UNIVERSITY, BELGOROD, RUSSIA
}

\begin{abstract}
The aim: To evaluate the structural and functional parameters of the cardiovascular system during atrial fibrillation (AF) in patients after a stroke.

Materials and methods: In the main group, we selected 28 patients with non-valvular AF who had previously suffered an ischemic stroke (IS). The comparison group (30 people) included patients with AF without a stroke, comparable in age and gender.

Results: As a result of the study, we discovered an increase in the risk of stroke with an increase in the thickness of the intima-media complex $>0.9 \mathrm{~mm}$. The thickness of the interventricular septum was $1.19(1.1 ; 1.25)$ in the group of patients with $I S$, and in the group of patients without $I S-1.09(1.0 ; 1.19) \mathrm{cm}(p=0.019)$, the thickness of the LV posterior wall is greater in the main group $1.14(1.05 ; 1.24)$ and $1.09(1.01 ; 1.18) \mathrm{cm}$ in the comparison group $(p=0.038)$. The myocardial mass index is 123.3 in the main group and $107.4 \mathrm{~g} / \mathrm{m} 2$ in the comparison group $(\mathrm{p}=0.41)$, which indicates left ventricle $(\mathrm{LV})$ hypertrophy in the main group.

Conclusions: thus, during AF in stroke patients, changes in the following structural and functional parameters of the cardiovascular system were discovered: an increase in the thickness of the interventricular septum, thickness of the posterior wall of the LV, and in the thickness of the intima-media complex.
\end{abstract}

KEY WORDS: ischemic stroke, non-valvular atrial fibrillation, echocardiography, heart

Wiad Lek. 2021;74(3 p.l):465-470

\section{INTRODUCTION}

Atrial fibrillation (AF) is an important medical problem due to its widespread and increased mortality rate, increasing the risk of stroke by 5 times and increasing the risk of general mortality by $40-90 \%$ [1].

According to Hannon N. et al, with the development of stroke in a patient, a fatal situation arises not only for the brain, but for the whole body, which leads to a deterioration in the general somatic status [2].

One of the risk factors for ischemic stroke (IS) is a decrease in the peak blood flow velocity in the left atrial appendage (LAA) according to echocardiography (EchoCG). In this case, it is believed that the indicator is associated with a risk of atrial thrombosis, regardless of the form and duration of $\mathrm{AF}$ [3].

According to Golukhova E.Z. when conducting transesophageal echocardiography in patients with AF, it was found that the parameters of the hemodynamics of the heart, in particular: a decrease in blood flow velocity in the LAA less than $30 \mathrm{~cm} / \mathrm{s}$ and the morphological type of LAA are predictors of intracardiac thrombogenesis [4].

There is evidence that a decrease in the ejection fraction of the left ventricle (LVEF) $<50 \%$ and an increase in LA over $42 \mathrm{~mm}$ increases the risk of LAA thrombosis in $\mathrm{AF}$ [5].

Basically, retrospective studies are conducted to study clinical or laboratory risk factors for thrombosis in $\mathrm{AF}$ patients who have had a cardioembolic stroke (CES). The anatomy and morphology of LAA describes the relationship between the formation of a thrombus in the LAA and complications of AF.

However, in recent years, many studies have proven that the most accurate criterion for the remodeling of the LA should be the volume index of the LA (index. LAV) [6]. It was proven that the volume of the LA correlates with the degree of atrial fibrosis [7]. There are data on the assessment of $\mathrm{LV}$ diastolic function (DF) in patients with $\mathrm{AF}$ as a predictor of recurrence of arrhythmia [8], however, there are still no accurate echocardiography parameters for stroke prediction. There are studies on the dysfunction of the LA (stanning), as a predictor of recurrence of arrhythmia and possible CES $[6,8]$. «This phenomenon is based on several mechanisms: an excess of calcium in the cytoplasm of myofibrils, hibernation of the atrial myocardium due to tachycardia, as well as atrial fibrosis» [9].

In AF, diastolic dysfunction (DD) is difficult to assess with echocardiography due to the absence of atrial contraction (peak A), it is impossible to identify the type of left ventricular diastolic dysfunction LVDD. Also, there is a constant variation of indicators with each reduction, which makes repeated measurements necessary in order to obtain the average value and identify $\operatorname{LVDF}[1,10,11]$.

There is the possibility of assessing DD using tissue dopplerography (TD): the speed of movement of the 
fibrous ring of the mitral valve (MV) is measured in the early filling phase of the left ventricle (E') and is an active component of diastole [12]. The ratio of the $\mathrm{E}$ ' to the peak E of the transmitral blood flow (E / E - i.e. the ratio of the rates of the early diastolic flow and the early diastolic movement of the myocardium) allows you to indirectly evaluate the pressure in the cavity of the LV. The ratio $(E / E '>15)$ which reflects the increase in pressure in the $\mathrm{LV}$ and the increase in the pressure of filling the $\mathrm{LV}$, is one of the key parameters for assessing LVDF in patients with AF [13]. This indicator correlates with the "tau» coefficient, which reflects a decrease in LV pressure during the relaxation period.

Caputo M. et al. believe that the measurement of E / E, as a criterion for assessing LVDD, should be mandatory for the echocardiography protocol in individuals with $\mathrm{AF}$, and treatment tactics for patients with LVDD and AF should include longer anticoagulant therapy [8]. However, till date, there are many questions regarding the accuracy of different methods for assessing LVDF in patients with AF.

Analyzing recent studies in patients with AF on echocardiography, it was revealed that the only risk factor for ischemic stroke (IS) is the presence of LV systolic dysfunction (LVSD) corresponding to LVEF $<40 \%$. When studying the data of trans esophageal echocardiography in ischemic stroke, evidence such as the presence of blood clots in the LAA, decrease in blood flow in the appendage less than $20 \mathrm{~cm} / \mathrm{s}$, the presence of spontaneous contrast, as well as atherosclerotic lesions of the aorta attest. [9].

It was found that in people with AF up to 60 years without structural heart disease, the risk of IS and systemic thromboembolic complications (TEC) is $1.3 \%$ over 15 years. Unlike patients older than 75 years, who, on the contrary, had a very high risk of stroke [14].

Thus, it seems important to us to evaluate the structural and functional parameters of the cardiovascular system for atrial fibrillation in stroke patients in order to identify echocardiography parameters that increase the risk of stroke and resulting from a stroke.

\section{THE AIM}

The purpose of our research was to evaluate the structural and functional parameters of the cardiovascular system during atrial fibrillation in patients after stroke.

\section{MATERIALS AND METHODS}

In connection with the aim, we selected 28 patients with non-valvular atrial fibrillation who had previously suffered an ischemic stroke, of which 18 (64.3\%) were men and 10 (35.7\%) were women, the average age of the patients was 69.6 $(62 ; 74)$, body mass index (BMI) $-29.20(24.6 ; 33.2) \mathrm{kg} / \mathrm{m} 2$. The selection was conducted at the "City Hospital No. 2 of Belgorod City State Budgetary Healthcare Institution» (from January 2018 to December 2019).

Written informed consent was obtained from patients to participate in the study, permission was also received from the Ethics Committee of the Belgorod State National Research University to conduct the study.

The comparison group (30 people) included patients with non-valvular AF without stroke and transient ischemic attacks (TIA), a history of comparable age: 19 (63.3\%) men and 11 (36.7\%) women. Inclusion criteria: presence of non-valvular AF; the presence of 2 points when calculating the risk of feasibility study on the scale of CHA2DS2-VASc in men and 3 in women. Patients with valvular AF (moderate to severe and severe mitral stenosis or mechanical prosthesis of heart valves), thyrotoxicosis, and a history of cancer were excluded from the study.

All the patients underwent laboratory diagnostics, electrocardiographic (ECG), echocardiographic (Echo) studies, ultrasound duplex scanning of the arteries of the brachiocephalic zone (ultrasound of the BCA), and also filled out an individual questionnaire, which indicated anamnesis with the date of onset of atrial fibrillation, accompanying stroke pathology and all medications that the patient was on.

Structural and functional parameters of the heart were evaluated on a GE VIVID 7 Vantage (Expert Class Digital Ultrasound System) ultrasound apparatus, a multi-frequency sensor 2.5-4 for cardiac research. Echocardiography was performed according to the standard technique in $\mathrm{M}$ and $\mathrm{B}$ modes and tissue dopplerography. Determination of LV ejection fraction (EF) using the Simpson method.

The assessment of the intima-media complex (IMC) and the percentage of stenosis of the carotid arteries (CA) was performed on the device in accordance with the Russian national recommendations for cardiovascular prophylaxis of 2017 [15]. The thickness of IMC CA (mm) was determined at three standard points. The increase was considered the thickness of the IMC $>0.9<1.3 \mathrm{~mm}$. Local thickenings of more than 1.3 were considered evidence of the presence of atherosclerotic plaque (ASP). The degree of stenosis of the carotid arteries was assessed using the criteria of the ECST method (European Carotid Surgery Method), in which the degree of stenosis of the bifurcation of the common carotid artery is calculated as the ratio of the difference between the maximum and free lumen of the vessel to the maximum diameter of the vessel, expressed in percentage [16].

Statistical processing of the material was carried out using the program "Statistica 6.0". The methods of descriptive statistics were used with the determination of the median $(\mathrm{Me})$, and the interquartile range with the lower and upper quartiles (Q1 - Q3). Quality indicators were expressed in percentage. All indicators are given in the SI system. To assess the significance of differences between groups in quantitative terms, the nonparametric Mann-Whitney test was used. The analysis of differences in qualitative characteristics in two independent groups was carried out by constructing contingency tables with the subsequent calculation of the $\chi^{2}$ Pearson's criterion and the Odd ratio, with the calculation of $95 \%$ CI. The normality of the distribution was checked using the Shapiro-Wilk test; an abnormal distribution was detected. Significant changes in the indicators were considered at which $\mathrm{p}<0.05$. 
Table 1. The dynamics of the structural and functional parameters of the cardiovascular system during atrial fibrillation in patients after stroke.

\begin{tabular}{cccc}
\hline Index & $\begin{array}{c}\text { Main group } \\
\mathbf{( n = 2 8 )}\end{array}$ & $\begin{array}{c}\text { Comparison group } \\
(\mathbf{n}=\mathbf{3 0})\end{array}$ & $\mathbf{p}$ \\
\hline Thickness IVS, cm & $1.19(1.1 ; 1.25)$ & $1.09(1.0 ; 1.19)$ & 0.019 \\
\hline Thickness LVPWd, cm & $1.14(1.05 ; 1.24)$ & $1.09(1.01 ; 1.18)$ & 0.038 \\
\hline LVMI, $\mathrm{g} / \mathrm{m} 2$ & $123.3(117.1 ; 129.4)$ & $107.4(101.6 ; 115.4)$ & 0.041 \\
\hline LVEDD, cm & $4.81(4.21 ; 5.48)$ & $4.76(4.1 ; 5.38)$ & 0.28 \\
\hline LVESD, cm & $3.42(2.67 ; 4.12)$ & $3.39(2.62 ; 4.1)$ & 0.19 \\
\hline LVEF Simpson, \% & $53.4(44.8 ; 61.5)$ & $55.12(45.9 ; 63.4)$ & 0.24 \\
\hline Width LAA, cm & $4.26(3.65 ; 4.81)$ & $4.23(3.69 ; 4.76)$ & 0.31 \\
\hline Length LAA, cm & $6.02(5.08 ; 6.9)$ & $5.86(5.03 ; 6.61)$ & \\
\hline Volume LAA, ml & $73.71(49.6 ; 87.2)$ & $71.2(48.1 ; 86.3)$ & 0.12 \\
\hline Volume index LAA, ml/m2 & $39.9(34.8 ; 44.7)$ & $37.6(31.4 ; 43.5)$ & 0.26 \\
\hline E/E', unit & $14.6(11.2 ; 17.4)$ & $13.8(10.1 ; 16.2)$ & 0.11 \\
\hline IMC CA, mm & $1.03(0.97 ; 1.1)$ & $0.91(0.84 ; 1.05)$ & 0.14 \\
\hline
\end{tabular}

Table 2. Ratio of odds to stroke risk

\begin{tabular}{ccc}
\hline Factor & OR & 95 \%Cl \\
\hline LVMI according to Echo & 2.596 & $1.253-5.712$ \\
\hline IM thickness CA & 5.534 & $2.629-11.612$ \\
\hline
\end{tabular}

\section{RESULTS}

Among the examined patients, a history of concomitant diseases were identified: Hypertension (HTN), coronary heart disease $(\mathrm{CHD})$, and chronic heart failure (CHF). The average duration of $\mathrm{AF}$ disease was $4.7(2.6 ; 6.4)$ years in the study group and $3.8(2.0 ; 5.1)$ years in the comparison group $(\mathrm{p}=$ 0.07). A stroke was suffered in the range of 4 to 19 months ago.

In the main group there were $9(32.13 \%)$ patients with paroxysmal AF, 10 (35.7\%) with persistent atrial fibrillation.

We identified a lack of commitment to taking anticoagulants. Only $12(42.87 \%)$ patients took direct oral anticoagulants (DOAC), 5 (17.86\%) took warfarin and 10 $(35.7 \%)$ - indicated only the intake of acetylsalicylic acid (ASA) and / or clopidogrel. 1(3.57\%) patient did not take antithrombotic drugs at all. In this case, the question about whether anticoagulants were prescribed, almost all patients (92.8\%) answered positively, the remaining 2 could not remember the purpose of these drugs.

In the study of previous antithrombotic therapy, the following indicators were in the comparison group: ASA and / or clopidogrel were received by 15 (50\%) people, warfarin -8 (26.7\%), novel oral anticoagulants (NOAC) - 7 (23.3\%).

In patients in the main group, the average score on the CHA2DS2-VASc scale was $4.5(3: 5)$ and in the comparison group $2.75(2 ; 4) \mathrm{p}=0.068$.

Currently, there is no single accurate echocardiographic parameter that is used to diagnose LV diastolic dysfunction in patients with $\mathrm{AF}$.

It is recommended to use echocardiographic examinations, including a comprehensive analysis of two-dimensional echocardiography, Doppler echocardiography, as well as color tissue Doppler ultrasound. [10, 17].
From table 1, it shows that when comparing the main group and the comparison group, statistically significant differences were found in the following indicators: thickness of the interventricular septum (IVS) -1.19 $(1.1 ; 1.25)$ in the group of patients with stroke, and not IS - $1.09(1.0 ; 1.19) \mathrm{cm}(\mathrm{p}=0.019)$, the thickness of the posterior wall of the left ventricle (LVPWd) is greater in the main group $1.14(1.05 ; 1.24)$ compared to $1.09(1.01 ; 1.18)$ $\mathrm{cm}$ in the comparison group $(\mathrm{p}=0.038)$. The myocardial mass index (LVMI) is $123.3(117.1 ; 129.4) \mathrm{g} / \mathrm{m} 2$ in the main group and $107.4(101.6 ; 115.4) \mathrm{g} / \mathrm{m} 2$ in the comparison group $(\mathrm{p}=0.041)$. This indicates LV hypertrophy in the main group.

LV sizes did not significantly differ: the end diastolic dimension of the left ventricle (LVEDD), the end systolic dimension of the left ventricle (LVESD). The ejection fraction of the left ventricle also did not have significant differences; in the group of patients with stroke, it was $53.4(44.8 ; 61.5) \%$ and $55.12(45.9 ; 63.4) \%$ in the group of patients without stroke $(\mathrm{p}=0.24)$.

The width of the LV in the first group was 4.26 (3.65; $4.81) \mathrm{cm}$, and in the second group - $4.23(3.69 ; 4.76) \mathrm{cm}$; without statistically significant differences. Similar results were obtained for the volume of the LV - $73.71(49.6 ; 87.2)$ $\mathrm{ml}$ in the main group and $71.2(48.1 ; 86.3)$ in the control group $(\mathrm{p}=0.26)$.

The LV volume index was above norm in both groups, which indicates the presence of LV DD in both groups, $(39.9(34.8 ; 44.7) \mathrm{ml} / \mathrm{m} 2$ in the main group and $37.6(31.4$; 43.5) $\mathrm{ml} / \mathrm{m} 2$ in the control group $(\mathrm{p}=0.11)$ ).

The ratio of the rates of early diastolic flow and early diastolic movement of the myocardium E / E' in the main group $14.6(11.2 ; 17.4)$ units and in the control group 13.8 $(10.1 ; 16.2)$ units did not differ significantly. 
The thickness of the intima-media in the main group was statistically significantly different $-1.03(0.97 ; 1.1)$ $\mathrm{mm}$ and $0.91(0.84 ; 1.05) \mathrm{mm}$ in the comparison group $(\mathrm{p}=0.021)$, which indicates an increased thickness of the arterial walls in patients and in our opinion is not as a result of a stroke, but on the contrary, a stroke could be a result of the thickening of the intima-media of the arteries of the brachiocephalic zone. In the group of patients with IS, the thickness of the intima-media exceeded the norm in the carotid arteries more than $0.9 \mathrm{~mm}$. In the main group, such patients were $19(67.8 \%)$, and in the comparison group only 7 patients $(23.3 \%) ; \mathrm{p}=0.01$.

Analyzing the ECG data, it was found that signs of LV hypertrophy were observed in 16 patients $(57.1 \%)$ in the main group and 12 patients $(40 \%)$ in the comparison group, $\mathrm{p}=0.043$.

We evaluated the association of indicators with the risk of stroke. The results of calculating the odds ratio, when conducting a one-factor analysis are presented in table 2 .

Table 2 shows that a significant association with the risk of stroke was identified by LVMI with echocardiography (evidence of left ventricular hypertrophy) and by the thickness of the intima-media of the CA.

\section{DISCUSSION}

We identified a lack of commitment to taking anticoagulants, despite the high risk of developing complications. The recommendation for the management of patients with atrial fibrillation and especially after ischemic stroke, the need for constant administration of anticoagulant therapy is clearly stated $[1,15]$.

Our data of previous antithrombotic therapy are comparable with the results of the study by A. Karpov, where ASA was received by $50.6 \%$ patients, $23.1 \%$ received warfarin, $8.3 \%$ - dabigatran, $19.4 \%$ rivaroxaban, and $4.3 \%$ received apixaban. [18].

The average score on the CHA2DS2-VASc obtained in our study is comparable with the data of other studies. There is a study of 281 patients with AF from Krasnoyarsk [19]. According to their register, in patients, the average score on the CHA2DS2-VASc scale was $3.6(2.0-5.0)$, which is also comparable to the data obtained from the international registry GARFIELD, in which the average score is 3.2, and European (PREFER in AF) - 3.4 points $[20,21]$.

The LV volume index was above norm in both groups, which indicates the presence of LV DD in both groups. A study by Gupta S. et al. proved that the most accurate criterion for the remodeling of LV should be considered the index of LA volume [6]. It was also proven that the volume of the LA correlates with the degree of atrial fibrosis [7], however, there are still no exact echocardiography parameters for predicting stroke.

The ratio of the rates of early diastolic flow and early diastolic movement of the myocardium E / E' in the main group and in the control group did not differ significantly. In the presence of AF, LVDF certainly suffers, but its assessment during arrhythmia is difficult $[21,22]$.
Association with the risk of stroke was identified by LVMI with echocardiography (evidence of left ventricular hypertrophy) and by the thickness of the intima-media of the CA. Our data are consistent with the results of a study by Nikolin D.U. et al. In their opinion, left ventricular hypertrophy according to echocardiography is associated with an increased risk of ischemic stroke [23].

We realized statistically significant differences between the groups using the following echocardiographic parameters: thickness of the interventricular septum, thickness of the posterior wall of the left ventricle and the left ventricular myocardial mass index in patients who have had ischemic stroke. When studying the sources, we did not find such results.

In our study, a significantly higher frequency of occurrence was found in patients whose intima-media thickness exceeded the norm in the group with ischemic stroke. A number of studies have shown that an increase in the risk of stroke was shown with an increase in the thickness of the intima-media complex of the carotid arteries of more than $0.9 \mathrm{~mm}[24,25]$.

The left atrial volume index was above norm in both groups in both groups, which indicates the presence of diastolic dysfunction of the left ventricle with atrial fibrillation. After all, it is the volume of the left atrium that correlates with the degree of atrial fibrosis and atrial fibrillation [6-8]. But, we were not able to determine the statistically significant differences in the left atrial volume index in patients with and without atrial fibrillation.

\section{CONCLUSIONS}

Thus, as a result of the study, we realized statistically significant differences between the groups using the following echocardiographic parameters: thickness of the interventricular septum, thickness of the posterior wall of the left ventricle and the left ventricular myocardial mass index in patients who have had ischemic stroke.

An increase in the risk of stroke was shown with an increase in the thickness of the intima-media complex of the carotid arteries of more than $0.9 \mathrm{~mm}$ and an increase in the left ventricular myocardial mass index. In our study, a significantly higher frequency of occurrence was found in patients whose intima-media thickness exceeded the norm in the group with ischemic stroke $67.8 \%$ and only $23.3 \%$ in the comparison group.

The left atrial volume index is higher than normal in both groups, $39.9(34.8 ; 44.7) \mathrm{ml} / \mathrm{m} 2$ in the main group and $37.6(31.4 ; 43.5)$ in the control group), which indicates the presence of diastolic dysfunction of the left ventricle with atrial fibrillation. However, we were not able to determine the statistically significant differences in the left atrial volume index in patients with and without atrial fibrillation.

\section{REFERENCES}

1. Powers W.J., Rabinstein A.A., Ackerson T. et al. Guidelines for the early management of patients with acute ischemic stroke. A guideline for healthcare professionals from the American Heart Association/ American Stroke Association. Stroke. 2018; 49: e46-e110. Doi: 10.1161/ STR.0000000000000158. 
2. Hannon N., Callaly E.L., Moore A.F. et al. Improved late survival and disability after stroke with therapeutic anticoagulation for atrial fibrillation: a population study. Stroke. 2011; 42:2503-2508. doi:10.1161/STROKEAHA.110.602235.

3. Grontkovskaya A.V., Borovkov N.N., Amineva N.V. Arterial'naya gipertenziya kak faktor riska vnutripredserdnogo tromboza u bol'nyh s fibrillyaciej predserdij neklapannoj etiologii. [Arterial hypertension as a risk factor of intra-atrial thrombosis in patients with atrial fibrillation of non-valvular etiology]. Klin. Med. 2016;94 (6):433-438. (In Russian). Doi 10.18821/0023-2149-2016-94-6-433-438.

4. Golukhova E.Z., Gromova 0.I., Arakelyan M.G. et al. Prediktory tromboza ushka levogo predserdiya i tromboembolicheskih oslozhnenij u bol'nyh s fibrillyaciej predserdij bez soputstvuyushchej klapannoj patologii i ishemicheskoj bolezni serdca. [Risk factors of left atrial thrombus and/ or thromboembolism in patients with nonvalvular, nonishemic atrial fibrillation] Creative Cardiology. 2017; 11 (3):262-72. (In Russian). Doi: 10.24022/1997-3187-2017-11-3-262-272.

5. Karnialiuk I.U., Rabtsevich V.A., Karnialiuk A.M. Ekhokardiograficheskie prediktory tromboza ushka levogo predserdiya u pacientov s persistiruyushcheĭ fibrillyacieĭ predserdii. [Echocardiography predictors of the left atrial appendage thrombus in patients with persistent atrial fibrillation]. Annaly aritmologii. 2014; 11 (3):170-176. (In Russian). Doi: 10.15275/annaritmol.2014.3.5.

6. Gupta S., Matulevicius S.A., Ayers C.R. et al. Left atrial structure and function and clinical outcomes in the general population. Eur Heart J. 2013; 34: 278-285. doi:10.1093/eurheartj/ehs188.

7. Lupu S., Mitre A., Dobreanu D. Left atrium function assessment by echocardiography - physiological and clinical implications. Med. Ultrason. 2014; 16(2):152-161. Doi: 10.11152/mu.201.3.2066.162. sl1am2.

8. Caputo M., Mondillo S. Echocardiography in the prediction of atrial fibrillation recurrence: a review. Journal of Atrial Fibrillation. 2012; 5(2):23-29. doi:10.4022/jafib.675.

9. Gromyko T.Y. Dinamika strukturno-funkcional'nyh harakteristik levogo predserdiya v prognozirovanii recidivov fibrillyacii predserdij. [The dynamics of the structural and functional characteristics of the left atrium in predicting the recurrence of atrial fibrillation] dis.... Cand. of Med. Sciences, 2018:1-28. (In Russian).

10. Nagueh S.F., Appleton C.P., Gillebert T.C. Recommendations for the evaluation of left ventricular diastolic function by echocardiography. Eur J Echocardiogr. 2009;10: 165-193.

11. Kamyshnikova L.A., Efremova 0.A. Diastolicheskaya disfunkciya pri hronicheskoj serdechnoj nedostatochnosti - osnovnye diagnosticheskie parametry i kriterii tyazhesti. [Diastolic dysfunction in chronic heart failure - basic diagnostic parameters and criteria of severity]. Belgorod State University Scientific bulletin. Medicine Pharmacy. 2009; 4 (59):913. (In Russian).

12. Maurer M.S., Spevack D., Burkhoff D., Kronzon I. Diastolic dysfunction can it be diagnosed by Doppler echocardiography? J Am Coll Cardiol. 2004;44:1543-1549. Doi: 10.1016/j.jacc.2004.07.034.

13. Leong D.P., De Pasquale C.G., Selvanayagam J.B. Heart failure with normal ejection fraction: the complementary roles of echocardiography and CMR imaging.J Am Coll Cardiol Img. 2010;3:409-420. doi:10.1016/j. jcmg.2009.12.011.

14. Hughes M., Lip G.Y. Stroke and thromboembolism in atrial fibrillation: a systematic review of stroke risk factors, risk stratification schema and cost effectiveness data. Thromb Haemost. 2008; 99: 295-304. Doi: 10.1160/TH07-08-0508.
15. Kardiovaskulyarnaya profilaktika 2017. Rossijskie nacional'nye rekomendacii. [Cardiovascular prevention 2017. National guidelines]. Russian Journal of Cardiology. 2018; (6):7-122. (In Russian). Doi: 10.15829/1560-4071-2018-6-7-122.

16. European Carotid Surgery Trialists' Collaborative Group. MRC European Carotid Surgery Trial: interim results for symptomatic patients with severe (70-99\%) or with mild (0-29\%) carotid stenosis. Lancet. 1991; 337: $1235-1243$.

17. Gromyko T.Y., Sayganov S.A. Dinamika diastolicheskoj funkcii levogo zheludochka u pacientov s fibrillyaciej predserdij pri razlichnyh sposobah vosstanovleniya sinusovogo ritma. [The dynamics of diastolic function of the left ventricle at patients with atrial fibrillation at various]. Meditsinskiy sovet. 2017; 12: 202-208. (In Russian). Doi: 10.21518/2079-701X-2017-12-202-208.

18. Karpov Yu.A. Issledovanie bezopasnosti i effektivnosti apiksabana u pacientov s neklapannoj fibrillyaciej predserdij v real'noj klinicheskoj praktike $v$ Rossii. [The Study of Safety and Efficacy of Apixaban in Patients with Nonvalvular Atrial Fibrillation in Real Clinical Practice in Russia]. Atmosphere. Cardiology News. 2018; 4: 3-12. (In Russian).

19. Tuchkov A.A., Gogolashvili N.G., Yaskevich R.A. Sostoyaniye i adekvatnost' antikoagulyantnoy terapii pri fibrillyatsii predserdiy v klinicheskoy praktike. [State and adequacy of anticoagulant therapy in fibrillation of precurities in clinical practice]. Lechashchiy vrach. 2018; 7:7-10. (In Russian).

20. Kakkar A.K., Mueller I., Bassand J.P. et al. International longitudinal registry of patients with atrial fibrillation at risk of stroke: Global Anticoagulant Registry in the FIELD (GARFIELD). American Heart Journal. 2012; 163 (1):13-9.e1. Doi: 10.1016/j.ahj.2011.09.011.

21. Kirchhof P., Ammentorp B., Darius H. et al. Management of atrial fibrillation in seven European countries after the publication of the 2010 Guidelines on atrial fibrillation: primary results of the prevention of the thromboembolic events - European Registry in Atrial Fibrillation (PREFER in AF). Europace. 2014; 16 (1):6-14. Doi: 10.1093/europace/eut263.

22. Baymukhanov A.M., Khamnagadaev I.A., Gendlin G.E., Nikitin I.G. Narushenie diastolicheskoj funkcii serdca pri fibrillyacii predserdij. [The disorder of diastolic function of heart under fibrillation of atria]. Medical Journal of the Russian Federation. 2017; 23 (2):101-106. (In Russian). doi: 10.18821/0869-2106-2017-23-2-101-106.

23. Nicolin D.Y., Fokina E.G., Grachev V.G. et al. Dopolnitel'nye kriterii stratifikacii riska ishemicheskogo insul'ta u pacientov s fibrillyaciej predserdij i odnim ne svyazannym s polom ballom po shkale CHA2DS2VASs obuslovlennym arterial'noj gipertoniej. [Additional criteria for stratifying the ischemic stroke risk in patients with atrial fibrillation and one non-sex-related score on the CHA2DS2-VASC scale due to arterial hypertension]. Ural Medical Journal. 2018; 3(159):5-11. (in Russian). Doi: 10.25694/URMJ.2018.03.030.

24. Lorenz M.W., Polak J.F., Kavousi M. et al. Carotid intima-media thickness progression to predict cardiovascular events in the general population (the PROG-IMT collaborative project): a meta-analysis of individual participant data. Lancet. 2012; 379(9831): 2053-62. Doi: 10.1016/ S0140-6736(12)60441-3.

25. Willeit P., Tschiderer L., Allara E. et al. Carotid Intima-Media Thickness Progression as Surrogate Marker for Cardiovascular Risk: Meta-Analysis of 119 Clinical Trials Involving 100667 Patients. Circulation. 2020; 142(7):621-642. Doi: 10.1161/CIRCULATIONAHA. 120.046361. 


\section{ORCID and contributorship}

Lyudmila A. Kamyshnikova: 0000-0002-6129-0625 A,B,C,D,E Olga A. Efremova: 0000-0002-6395-1626 $6^{A, D, E, F}$

Ekaterina V. Bondarenko: 0000-0003-4515-7178 ${ }^{B, D, E}$

Natalya I. Obolonkova: 0000-0003-1595-3501 ${ }^{A, B}$

Olga A. Bolkhovitina: 0000-0002-8331-6873 ${ }^{F}$

Maryam W. Yusuf: 000-0001-9358-5906 ${ }^{\mathrm{C}}$

\section{Conflict of interest}

The Authors declare no conflict of interest

\section{CORRESPONDING AUTHOR}

Lyudmila A. Kamyshnikova

Belgorod State University

85 Pobedy St., 308015 Belgorod, Russia,

tel: 89045337334

e-mail: kamyshnikova@bsu.edu.ru

Received: 30.07 .2020

Accepted: 14.01 .2021

A - Work concept and design, B - Data collection and analysis, C - Responsibility for statistical analysis,

D-Writing the article, $\mathbf{E}$ - Critical review, $\mathbf{F}$ - Final approval of the article 